\title{
Underemployment and psychological distress: Propensity score and fixed effects estimates from two large UK samples
}

\author{
Victoria Mousteri $^{\mathrm{a}, *}$, Michael Daly ${ }^{\mathrm{b}, \mathrm{c}}$, Liam Delaney ${ }^{\mathrm{a}, \mathrm{c}}$ \\ ${ }^{a}$ University of Stirling, Scotland, United Kingdom \\ ${ }^{\mathrm{b}}$ Maynooth University, Ireland \\ ${ }^{\mathrm{c}}$ UCD Geary Institute, University College Dublin, Ireland
}

\section{A R T I C L E I N F O}

\section{Keywords:}

UK

Hours-underemployment

Working-hours preferences

Employment transitions

Psychological distress

\begin{abstract}
A B S T R A C T
Background: The share of workers who work part-time because full-time jobs are not available remains larger compared to the period prior to the 2008 crisis. For part-time workers, being available to work more hours than offered may have negative mental health implications.

Method: Drawing on two nationally representative British surveys, we tested whether working less than 30 hours per week while preferring to work longer hours (underemployment) is associated with increased psychological distress. Distress was assessed using responses to the 12-item General Health Questionnaire in both samples. Results: In the National Child Development Study $(N=6,295)$, propensity score estimates indicated that the hours-underemployed workers experienced higher levels of psychological distress $(\beta=0.25, p<0.001)$ than full-time workers matched on observable characteristics, including prior distress levels. Fixed effects estimates using 18 years of the British Household Panel Survey $(N=8,665)$ showed that transitioning from full-time employment to underemployment predicted an increase in distress levels $(\beta=0.19, p<0.01)$. Conversely, transitioning from underemployment to full-time employment forecasted a reduction in distress $(\beta=-0.18$, $p<0.001)$. On average, job earnings and perceptions of job security explained a small $(\approx 10 \%)$ portion of the potential psychological impact of hours-underemployment.

Conclusions: These findings highlight the possibility that underemployment among part-time workers may have detrimental psychological consequences. Policy interventions geared towards improving career opportunities for part-time workers would potentially ameliorate losses in psychological well-being experienced by this group.
\end{abstract}

\section{Introduction}

Unemployed people are more likely to suffer from poor mental health than the employed, and the psychological effects of unemployment appear to be substantial and long-lasting (Daly and Delaney, 2013; Paul and Moser, 2009). Yet, employment does not guarantee positions where people are working at their full capacity. Underemployment occurs where workers are underutilised either in terms of working hours or the degree to which their skills and qualifications are effectively used or financially rewarded.

In this study, we focus specifically on time-related or underemployment, which is defined by the International Labour Organisation (ILO) as those who work fewer hours than a national-specific threshold related to working time while they are willing and available to work additional hours (ILO, 1998). Recent labour market statistics suggest that time-related underemployment rose quickly to historically high levels during the Great Recession (Bell and Blanchflower, 2013; OECD, 2010). According to a recent report issued by Office of National Office for National Statistics (2018), around $12 \%$ of part-time workers in the UK reported that the reason for working part-time was that they were not able to find a full-time job. While part-time employment was relatively stable during 2018, the share of underemployment was higher than in the period prior to the crisis.

There are numerous reasons why hours-underemployed workers may experience elevated levels of dissatisfaction and psychological distress. First, it has long been argued that employment has positive welfare benefits because of the manifest (e.g., salary and the production of goods) and latent functions (e.g., time structure, social contact, collective purpose, social status, activity) that work provides (Jahoda, 1982). The reduced income associated with underemployment may place financial strain on individuals generating distress (Koltai et al., 2018). Hours-underemployed workers also experience reduced contact

\footnotetext{
${ }^{*}$ Corresponding author.

E-mail addresses: victoria.mousteri@stir.ac.uk,v.mousteri@gmail.com (V. Mousteri).
} 
with the workplace, which may limit the psychosocial benefits of work, such as social contact and support, having a sense of being useful and needed by others, being active, and having a structured experience of time. Prior research suggests that failure to adequately satisfy these needs through employment may provoke distress (Paul and Batinic, 2010).

A set of theories have also been applied specifically to understanding why underemployment may generate dissatisfaction and distress. Conservation of resources theory ( $\mathrm{Ng}$ and Feldman, 2014; Hobfoll, 1989) suggests that workers may become underemployed because they accept positions that do not meet their expectations in an attempt to protect threatened resources and avoid further losses (e.g., becoming unemployed). While becoming hours-underemployed may serve the function of conserving resources, relative deprivation theory posits that such workers are likely to feel dissatisfied (Feldman et al., 1997). Under-employed workers may perceive their employment situation as inferior to that of other workers (e.g., those who work as many hours as they wish) or that the work situation does not match their skills or desires. The person-job fit framework also suggests that hours-underemployed workers may feel more negative about their jobs compared to others because of the stark discrepancy between the hours of work the employee desires and the hours the job offers (McKee-Ryan and Harvey, 2011).

The coping and control theory model of reemployment (Latack et al., 1995) of job search posits that workers will be motivated to reduce such discrepancies. Doing so enables employees to move closer to a state of equilibrium and feel satisfied that their employment goals and job situation match. As such, being hours-underemployed may also shape time use, leading to increased investment in the arduous and often distressing job search process.

In this study, we focus on the share of part-time workers who would prefer to work more hours, as this group potentially experiences the most adverse consequences of part-time employment. As noted above, extensive theory suggests this group may be dissatisfied with their current positions and experience increased financial difficulties, declines in self-esteem, and increased job insecurity distress (Friedland and Price, 2003). For example, Warren (2015) showed that part-time workers experienced elevated financial hardship following the recession in the United Kingdom (UK) while they were more likely to be in underemployment compared to full-time workers.

Using the Organisation for Economic Co-operation and Development's (OECD) conventional definition of part-time employment (see, for example, OECD, 2018) and ILO's underemployment definition, we specifically consider those who work less than $30 \mathrm{~h}$ per week while preferring to work more hours at the same wage rate as being hours-underemployed. The 30 -h cut-off points appears to represent prevailing conditions in non-standard employment in the UK's labour market since the late 1990s (Bardasi and Francesconi, 2004; Booth and Francesconi, 2003). Using more recent data, Kamerade and Richardson, 2018 showed that the vast majority of part-time workers in the UK appear to work less than $30 \mathrm{~h}$ per week.

Working part-time does not translate into reduced health insurance benefits in the UK and thus, the potential detrimental impact of hours underemployment is not likely to be driven by reduced access to healthcare. However, underemployment has been linked to unfavourable work outcomes, such as financial hardship, poor job quality, earnings inequality, and lower occupational status (McGovern et al., 2004; OECD, 2014 ). Those who are in part-time employment and desire to work more hours often find themselves in low-wage, precarious jobs, which underutilise their skills and abilities, hindering access to rewarding occupations in the long-run ( OECD, 2014). Moreover, socioeconomic adversities have been shown to follow exposure to underemployment, including financial strain (Warren, 2015), in-work poverty (Horemans et al., 2016), and reduced family well-being (Lepinteur, 2019; Wunder and Heineck, 2013). While it is likely that such effects may mean that underemployment leads to negative psychological consequences, this pattern has not yet been established using robust empirical methods across multiple national samples. Therefore, in this study, we aimed to decipher whether this unsatisfactory employment situation predicts increased psychological distress in two large surveys using propensity score matching and fixed effects models.

Prior work has drawn linkages between underemployment, increased depressive symptoms, low self-esteem (Dooley et al., 2000; Friedland and Price, 2003; Prause and Dooley, 1997), declines in mental health (Milner and LaMontagne, 2017), lower life satisfaction and well-being (Friedland and Price, 2003; Heyes et al., 2017; Kamerade and Richardson, 2018; Wilkins, 2007), and increased suicide rates (Page et al., 2013). Aside from notable exceptions (e.g. Milner and LaMontagne, 2017), previous research in this area has been hampered by design limitations, including reliance on cross-sectional samples with limited controls (Page et al., 2013), inadequate adjustment for bias due to self-selection into underemployment (Heyes et al., 2017; Kamerade and Richardson, 2018; Wilkins, 2007), and the use of divergent approaches to assessing underemployment not well aligned with recognized definitions (Heyes et al., 2017; ILO, 1998). In contrast, we suggest that examining closely matched samples and panel data where transitions between full-time employment and underemployment can be observed over prolonged periods will likely yield less biased estimates of the link between underemployment and distress (Friedland and Price, 2003; Prause and Dooley, 1997).

There are currently two lines of longitudinal evidence that suggest that underemployment may have notable mental health effects. First, prior research suggests that a reduction in the number of hours worked per week may have negative well-being effects. For instance, moving from working full-time to part-time jobs (i.e., working between 16 and $29 \mathrm{~h}$ per week) has been shown to predict a reduction in life satisfaction, at least amongst women in the UK (Bardasi and Francesconi, 2004). Further, Booth and Van Ours (2008) found that full-time employees are happier than part-time employees after controlling for endogeneity using fixed effects logit models, implying that working parttime may have a detrimental welfare effect. These studies do not consider individual working hour preferences and as such cannot identify whether the adverse well-being effect of part-time employment is predominantly experienced by those who wish to work more hours.

A second line of evidence supports the contention that working less hours than desired has been shown to predict reduced life satisfaction (Başlevent and Kirmanoğlu, 2014; Wooden et al., 2009; Wunder and Heineck, 2013). For instance, Başlevent and Kirmanoğlu (2014) examine the well-being effect of differences between preferred and actual working time in a cross-country panel at a single point in time. They show that working fewer hours than preferred reduces life satisfaction across Europe. Further, Wunder and Heineck (2013) use a longitudinal sample of German workers, which allows controlling for unobserved heterogeneity and potential self-selection bias. They find that working fewer hours than desired is more harmful for subjective well-being compared to working more hours than ideally preferred. Angrave and Charlwood (2015) showed that working less hours than preferred predicts lower life satisfaction and psychological well-being, particularly among female workers who work less than $35 \mathrm{~h}$ per week in the UK.

Together, these two lines of evidence show that a reduction in the number of hours worked per week may have negative well-being effects (Bardasi and Francesconi, 2004; Booth and Van Ours, 2009; Rodriguez, 2002), and that working less hours than desired predicts reduced life satisfaction (Başlevent and Kirmanoğlu, 2014; Wooden et al., 2009; Wunder and Heineck, 2013).

Our study employs robust estimation procedures to evaluate whether hours-underemployed workers show particularly pronounced psychological effects. Specifically, we explore the potential contribution of underemployment to psychological distress using propensity score matching in a sample of UK workers drawn from the National 
Child Development Study (NCDS) age-42 sweep. Furthermore, we test whether individual transitions between full-time employment and underemployment predict subsequent increases in distress levels in a sample of British adults drawn from the 18 consecutive waves of the British Household Panel Survey (BHPS, 1991-2008) using individual fixed effects models.

Finally, we examine whether poor job security and reduced earnings may explain the psychological impact of hours-underemployment. Those experiencing underemployment tend to view their positions as more insecure than full-time employees (Kim et al., 2008), which could generate psychological distress (Ferrie et al., 2002; Sverke et al., 2002; Virtanen et al., 2002). Moreover, consequences of underemployment such as low income and financial strain have been shown to be reliably associated with poor mental health (Zimmerman and Katon, 2005).

\section{Method}

\subsection{Study 1}

\subsubsection{Population}

The NCDS is a longitudinal survey following participants born in a single week of 1958 in England, Scotland, and Wales. We used the sixth wave of the survey that was conducted from 1999 to 2000 $(N=11,419)$ with participants that were age 42 for the analysis of the contemporary psychological impact of hours-underemployment. This wave features a question about cohort members' preferences regarding the number of hours they work at their current job. In addition, we utilised measures from the third, fourth, and fifth sweep (ages 11, 23, and 33) to account for key socio-economic and individual difference characteristics, which may affect both employment status and psychological distress, such as highest educational achievement, prior psychological distress, and cognitive abilities during childhood.

Around $10 \%$ of observations on earnings, occupational status, and educational qualifications are missing. We used mean imputation to replace missing values in order to arrive at estimates of the effects of interest using the full sample. Following Sidi and Harel's (2018) suggestion on reporting handling of missing data, we compare findings using mean replacement to findings using complete case analysis. As shown in Table A3 in Appendix A in the Supplementary Materials, the impact of underemployment on psychological distress does not change substantially in complete case analysis. While standard errors increase as a result of smaller sample sizes, similarities in the magnitude of the coefficients and the impact of including covariates suggest that our main estimates capture the detrimental psychological impact of underemployment, as well as the contribution of earnings and job security.

\subsubsection{Measures}

2.1.2.1. Hours-underemployment. The study sample comprises all study subjects who reported that they were either in paid employment or selfemployed. Adopting two criteria of the definition of underemployment provided by the ILO (1998), current exposure to underemployment was measured using an indicator that combined two survey questions; one detailing study subjects' main economic activity and a second asking whether they would prefer to work more, fewer, or the same hours per week for the same hourly rate. Two basic groups were constructed: (i) a reference group consisting of those who reported that they were working more than $30 \mathrm{~h}$ per week and did not want to work more or less hours $(N=4,135,90.7 \%)$, and (ii) the hours-underemployed who were working less than $30 \mathrm{~h}$ per week and would prefer to work more hours $(N=423,9.3 \%)$. The high share of women in the hoursunderemployed group (89.6\%) is representative of the trends prevailing in the UK labour market during the 1990s, with the vast majority of the part-time workforce being female (Fagan et al., 2013).

Supplementary analyses were conducted using alternative groups of part-time and full-time workers to test whether the psychological impact of underemployment could be attributed specifically to either employment type or working-hours preferences. The following groups were created to examine average differences in their psychological distress levels: (i) part-time workers $(<30 \mathrm{~h}$ per week) who would not change the number of hours they work per week $(N=1,410,25.4 \%)$ and full-time workers ( $>30 \mathrm{~h}$ per week) with similar preferences ( $N=4,135,74.6 \%)$; (ii) part-time workers who would rather work more hours $(N=423,56.5 \%)$ and full-time workers who would prefer the work more $(N=325,34.5 \%)$, and (iii) full-time $(N=4,460$, $70.9 \%)$ and part-time workers $(N=1,835,29.1 \%)$, without considering their working-hours preferences. We used the third group to test whether the interaction between employment type and hours preferences is a determinant of psychological distress.

2.1.2.2. Psychological distress. Psychological distress was assessed using the 12-item General Health Questionnaire (GHQ-12), a simple screening tool used to detect general non-psychotic, psychiatric morbidity (Goldberg and Williams, 1988). The items primarily capture affective disorders focusing on depression and anxiety (e.g., "feeling unhappy and depressed", "lost much sleep over worry"). In addition, the GHQ-12 gauges social dysfunction (e.g., "able to face problems", "playing a useful part"). Measures created using responses to the GHQ-12 are widely used among economists as psychological health indicators (e.g. Clark et al., 2001; Cornaglia et al., 2015). The cohort members were asked to report the frequency of the symptoms they suffered from on a scale ranging from 1 ("not at all") to 4 ("much more/ less than usual"). For each item, a binary variable was created for responses falling in the categories 3 and 4, indicating psychiatric caseness (Makowska et al., 2002), which is defined as being "at the risk" of suffering from mental health problems. The 12 binary indicators were then summed to produce a composite psychological distress index ranging from 0 to $12(\mu=1.48, S D=2.26)$, which demonstrated high levels of internal consistency (Cronbach's $\alpha=0.87$ ). A standardised GHQ-caseness score was utilised to facilitate comparisons between the two studies and the broader literature.

2.1.2.3. Covariates. We adjusted for the influence of the following confounding characteristics: gender, marital status, having any children, long-standing health conditions, highest educational qualifications, psychological distress at age 23, and cognitive ability during childhood (Deary et al., 2005; Koenen et al., 2009), which could influence both adult employment outcomes and psychological health. Moreover, we used variables on having children six years old or younger and/or babies born the year of data collection or one year before in order to examine whether the impact of underemployment on psychological distress is the outcome of workers in parenthood struggling with work-life balance. We also added a set of controls for workers' sector of occupation reflected in SOC codes to explore the contribution of different sectors in the psychological impact of hours underemployment.

Finally, we considered two job-related characteristics that may explain the relationship between hours-underemployment and psychological distress: (i) perceived job security (initially rated from $1=$ very secure to $3=$ not very secure and reversed) and (ii) weekly net takehome pay (in UK pounds) from current job. Mean imputation was applied to handle missing values. The descriptive statistics of all variables discussed in this section are presented in Table A1 in the Supplementary Materials.

\subsection{Statistical analysis}

Our objective in this study was to examine the contemporary impact of underemployment on psychological distress at a single point in time. Because the NCDS respondents are not randomly assigned to employment types, it is important to adjust for individual characteristics, which could result in self-selection into underemployment, potentially 
leading to overestimation of this association. To reduce self-selection bias, we balance the distributions of observable confounding factors across both employment groups (full-time workers satisfied with hours vs. part-time workers who desire to work more hours) using propensity score matching (Dehejia and Wahba, 1999; Stuart, 2010). The propensity, or "balancing," scores $\left(P S_{i}\right)$ are the probabilities that each cohort member will enter underemployment conditional on various sociodemographic factors. We estimate the propensity scores for each study subject as a function of the factors potentially predicting both underemployment and poor psychological health. Study participants from the group of interest (hours-underemployed workers) are then matched to those belonging to the reference group (full-time workers who are satisfied with the number of hours they work per week) on the basis of the differences between their estimated balancing scores $\left(D S_{i j}\right)$, where $P S_{i}$ and $P S_{j}$ are the propensity scores for individuals in the group of interest and the reference group, respectively:

$D S_{i j}=\left|P S_{i}-P S_{j}\right|$

We set the maximum difference $\left(D S_{i j}\right)$ between the propensity scores of hours-underemployed and full-time workers allowed for matching to be equal to 0.2 standard deviations of the estimated propensity scores $(S D=0.120)$. While a maximum distance of 0.25 standard deviations of the propensity score is suggested as a universal rule of thumb (Rosenbaum and Rubin, 1985), Stuart (2010) argues that a 0.2 standard deviation maximum distance reduces potential bias in estimating the contribution of covariates in the propensity scores when the propensity score variance in the treatment group is larger than in the control group.

Adopting the radius matching technique, we pair each hours-underemployed worker with all full-time workers with propensity scores that fall within this maximum distance (radius $=0.2 S D$ of the propensity scores) (Caliendo and Kopeinig, 2008). Radius matching produces matches of study subjects from the group of interest with all the control units that fall within the maximum distance. Therefore, all observations that are available in the sample are used when good matches are feasible (Dehejia and Wahba, 2002). A sample is then created using normalised weights, which reflect the frequency with which each full-time worker was used as a match to an hours-underemployed worker. Detailed information regarding the characteristics of the matched sample is presented in Appendix A, Section 2 of the Supplementary Materials.

The matched sample is then used to examine the influence of underemployment on psychological health. Average psychological distress is modelled as a function of individual socio-economic background and employment status:

$h^{*}\left(E\left[D_{i}\right]\right)=\left(P T_{i}, X_{i}^{S}\right)$

where $E\left[D_{i}\right]$ is average psychological distress, $P T_{i}$ is an indicator showing exposure to underemployment and $X_{i}^{S}$ is a vector of socioeconomic background variables. $h^{*}$ represents the identity link function, linking average psychological distress to employment type and demographic background. Equation (2) is estimated using the following empirical specification:

$E\left(D_{i}\right)=\alpha+\beta P T_{i}+\gamma_{S}\left(X_{1}+X_{2}+\ldots+X_{S}\right)+e_{i}$

where $\beta$ represents the average effect of interest and $e_{i}$ is the error term. Job related characteristics are included in the model at a later stage, to examine whether they mediate the psychological impact of hours-underemployment.

To explore the upper boundaries of the effects of interest, specification 3 is estimated adopting the ordinary least square (OLS) technique in the unmatched sample. Then, we estimate the effect of underemployment on the population average value of psychological distress in the matched sample. We adopt the Generalised Estimating Equations (GEE) method for clustered data to account for correlated outcomes in the matched pairs as done previously in samples

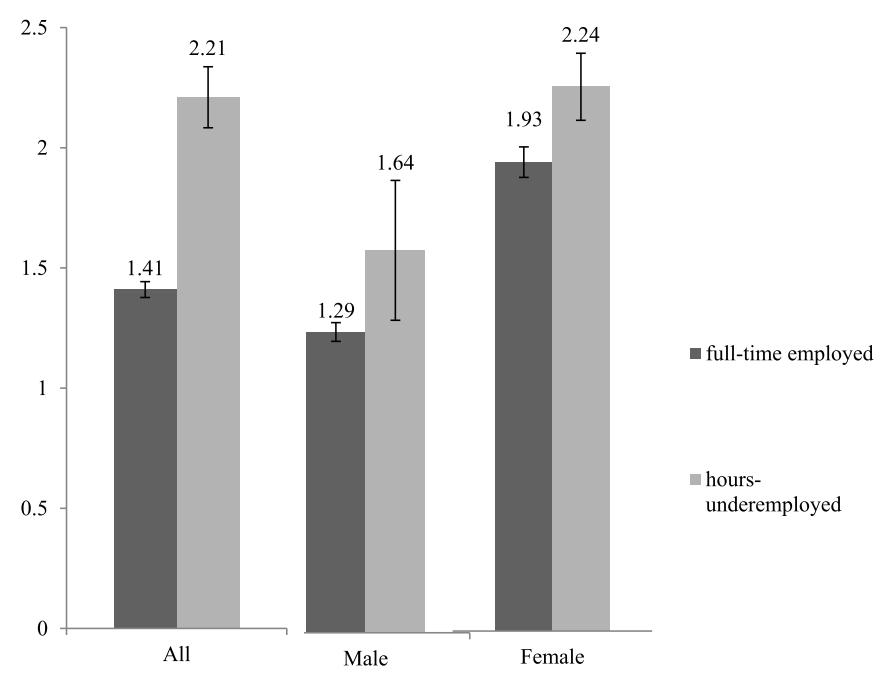

Fig. 1. Mean psychological distress by employment type and gender. This figure shows differences in self-reported psychological distress among male and female employees in full-time employment and underemployment (i.e., parttime but prefer full-time).

constructed using propensity score matching (see, for example, Kim et al., 2008). The GEE method uses weighted combinations of the observations in the correlated pairs to generate estimates of the impact of the explanatory variables on the expected (mean) value of the outcome of interest (Burton et al., 1998; Hanley et al., 2003).

\subsection{Results}

\subsubsection{Association between underemployment and distress}

As shown in Fig. 1, underemployment was associated with elevated psychological distress, with the mean difference in GHQ-12 caseness scores between the two groups being 0.8 points $(\mathrm{B}=-0.8, \mathrm{SE}=0.11$, $\mathrm{p}<0.001,95 \%$ CI $[-1.03,-0.58])$. Moreover, we found that hoursunderemployed workers of both genders experienced substantially higher distress levels compared to their full-time counterparts of the same sex, indicating that the psychological health repercussions of underemployment are not likely to be attributable to gender differences.

\subsubsection{Underemployment regressions}

We first examined the relationship between psychological distress and underemployment in the unmatched sample using models estimated using the ordinary least squares method. As shown in the upper panel of Table 1, underemployment was associated with elevated distress scores $(\beta=0.24, S E=0.06, p<0.001,95 \% C I[0.13,0.35])$, after controlling for socioeconomic background. Further controlling for earnings and self-evaluated job security in separate specifications slightly reduces the coefficient of interest (by 10.8\%), as shown in the last rows of the upper panel of Table 1.

\subsubsection{Propensity score matching estimates}

The link between underemployment and psychological distress was then estimated applying the GEE technique in the matched sample. As shown in Table 1, the estimate of the average effect of underemployment on psychological distress conditional on socio-economic characteristics was approximately $0.25 S D(\mathrm{SE}=0.06, p<0.001,95 \%$ $C I[0.13,0.37])$. Adjusting for self-selection into underemployment does not offset its adverse effect on psychological well-being. 
Table 1

Underemployment and Psychological Distress at age 42 in the National Child Development Study using Ordinary Least Squares (top panel; $N=4558$ ) and Propensity Score Matching (estimated using the Generalised Estimating Equations technique) Models (bottom panel; $N=4557$ ).

Unmatched sample $(O L S)$

Psychological Distress

$\beta(S E)$

Underemployment $^{\mathrm{a}}$
+ socio-economic confounders $^{\mathrm{b}}$
+ weekly net earnings
+ job security
Matched sample (GEE)
Underemployment (part-time but prefer full-time)
+ socio-economic confounders
+ beekly net earnings
+ job security

$0.339 * * *(0.056)$

$0.241^{* * *}(0.057)$

$0.229 * * *(0.060)$

$0.215^{* * *}(0.057)$

$0.252^{* * *}(0.063)$

$0.249 * * *(0.061)$

$0.261 * * *(0.071)$

$0.228^{* * *}(0.062)$

$* * * p<0.01, * * p<0.05, * p<0.1$.

Note. Standardised coefficients are reported. Standard errors are included in parentheses.

a Model does not include controls.

b Socioeconomic confounders are gender, marital status, having at least one child, highest academic qualification achieved at age 33, distress level at age 23 , long-standing illness, childhood cognitive ability, and occupational status at age 33 .

Furthermore, the potential negative psychological repercussions of underemployment are evident after controlling for both financial returns and self-perceived job security, indicating that there are other, unidentified mechanisms driving the observed psychological impact of hours-underemployment.

\subsubsection{Supplementary analysis}

Supplementary analysis controlling for having young children under the age of six and/or babies showed that the observed effects do not appear to be driven by the impact of parenthood on psychological wellbeing of workers. Moreover, accounting for the impact of workers' sector of occupation minimally altered the results (see Section 5 of Appendix A in Supplementary Materials).

Moreover, we conducted additional analysis applying the same propensity matching and GEE methodology on samples comprising alternative groups of part-time and full-time workers with respect to individual preferences about working time. As shown in Table A2 of the Supplementary Materials, when preferring to continue working the same number of hours per week, part-time employment was not substantially associated with elevated distress levels compared to full-time employment ( $\beta=0.037, S E=0.039, p>0.1,95 \% C I[-0.06,0.10]$ ). In contrast, comparing full-time to part-time contracts among workers who would prefer to increase their working hours revealed substantially elevated distress levels for part-time workers before accounting for jobrelated characteristics $(\beta=0.209, S E=0.106, p<0.05,95 \% C I$ [0.002, 0.42]).

Adjusting for weekly earnings and feelings about job security in this group of workers who would prefer to work more hours offsets the link between underemployment and psychological distress by $16.3 \%$. This finding suggests that part-time employment may be worse for psychological health compared to full-time employment for reasons other than working hours preferences - for example, because of poor quality of part-time jobs, reflected in lower earnings and job insecurity.

Furthermore, interacting employment type with an indicator for preferences for increased working hours showed that working part-time and wanting to work more hours increases psychological distress levels $(\beta=0.19, S E=0.11, p<0.1,95 \% C I[-0.03,0.41])$. In summary, the results of Study 1 indicate that part-time employment may be a psychologically harmful experience for workers who prefer to work more hours, with alternative specifications further supporting this key result.

\section{Study 2}

\subsection{Method}

\subsubsection{Population}

The BHPS was used to examine the relationship between employment transitions and variation in psychological distress over 18 years (1991-2009). The BHPS is a household-based, longitudinal survey, annually interviewing adult members of a clustered, stratified sample consisting of 5500 households around the UK. In subsequent waves, all household members who became 16 years old were added in the survey. Additional samples of households in Scotland, Wales, and Northern Ireland were added in 1999 and 2001. Wave-on-wave response rates were quite high for each wave; for example, $87.7 \%$ in wave 2 and $96.8 \%$ in wave 13 . Participants reported their employment status along with a range of details about their lives each year including their psychological distress levels and their perceptions regarding their jobs (Taylor, 2010). Thus, it is possible to assess whether within-person changes in labour market status may affect psychological distress levels over time.

Less than $2 \%$ of data in the subsample of respondents transitioning from underemployment to full-time employment and the subsample of respondents moving from full-time employment to hours underemployment were not reported. While our main analysis relies on mean imputation to arrive at estimates of the relationships of interest using the full sample, compete case analysis was also conducted. Using this method did not substantially alter the results suggesting that the estimated impact of transitions between underemployment and full-time employment does not depend on assumptions regarding handling of incomplete data (Tables B4 and B5 in the Supplementary Materials).

\subsubsection{Measures}

3.1.2.1. Hours-underemployment. As in Study 1, we defined underemployment as working less than $30 \mathrm{~h}$ per week while preferring to work more hours. The participants who reported that they worked more than $30 \mathrm{~h}$ per week and wanted to continue working the same number of hours were considered to be in full-time employment. The employment type variable lagged one period $(t-1)$ was used to create binary indicators capturing the annual transitions between full-time employment and hours-underemployment. 15,134 employed or self-employed study subjects of working age (16-65 years old), who have participated in at least two consecutive waves and have valid information regarding their labour market status and their psychological health in each wave were selected out of the 32,380 participants in the original, pooled sample. Annual employment transitions were observed in two subsamples, which were created based on comparisons between type of employment and workinghours preferences at years $t$ and $t-1$. The psychological effect of moving from underemployment to full-time employment was examined in a subsample of approximately 801 subjects who were hours-underemployed in year $t-1$. In this subsample, around $20.7 \%$ of the 2145 employment episodes recorded annually over the 18 consecutive waves of the BHPS corresponded to transitions from underemployment to full-time jobs. The psychological impact of annual transitions from full-time jobs to underemployment was examined using a subsample of 7864 study subjects who were working full-time in year $t-1$. Only $0.57 \%$ of the 37,234 person-year observations in each wave corresponded to switching from full-time employment to hours-underemployment.

In order to examine whether employment type or hours preferences produce the harmful well-being impact of underemployment, we tested alternative specifications, as in study 1 . Namely, we examined the impact on variations in psychological distress of the following transitions: (i) moving between full-time and part-time jobs when satisfied with weekly working hours; (ii) moving between full-time and part-time jobs while preferring to work less hours; (iii) moving from full-time to part- 
time employment conditional on preferring to work more hours, as identified by an interaction term. Descriptive information about sample sizes and transitions prevalence in these alternative specifications is presented in Table B1 in the Supplementary Materials.

3.1.2.2. Psychological distress. Similar to Study 1, psychological distress was assessed using responses to the 12-item GHQ questionnaire. The caseness version of the GHQ-12 score was examined in all BHPS waves and ranged from 0 to 12 . This variable was standardised to facilitate comparisons across studies and provide an indication of the magnitude of the association between underemployment and distress.

3.1.2.3. Covariates. As in Study 1, we aimed to incorporate available measures of socio-economic characteristics to once again control for observed individual heterogeneity which may result in self-selection into hours-underemployment. Gender, marital status, having any children, long-standing health problems, occupational status of participants' current job and highest educational achievement were controlled for. As in Study 1, women were over-represented in the hours-underemployed group, reflecting the typical composition of the group of part-time workers in the UK during the 1990s. We also accounted for the influence of age on the association between employment transitions and distress. Controls for having young children up to the age of six and/or babies were included in supplementary analysis that explores the contribution of early parenthood to the observed effects. Additional analysis was also carried out using controls for workers' sector of occupation (based on the SOC classification) to examine whether working in different sectors can explain the psychological effects of transitioning between full-time employment and hours-underemployment.

Moreover, we examined whether weekly net rate of take-home pay, adjusted for inflation using the ILO's series for consumer price indices in the UK, and participants' satisfaction regarding job security explain the psychological impact of employment transitions. The descriptive statistics of all variables discussed in this section are presented in Table B1 of the Supplementary Materials.

\subsubsection{Statistical analysis}

We assume that moving between underemployment and full-time employment can predict changes in psychological health over time. We model such changes in psychological distress $(\Delta D)$ as a function of employment transitions and changes in individual socioeconomic background variables (outlined above):

$\triangle D=f($ Transition, $\triangle S E S)$

First, we estimate the following specification that models the relationships between transitions and psychological health using the ordinary least squares technique for each type of transition:

$D_{i t}=a+\beta_{1}$ Transition $_{i t}+\beta_{2 S}\left(X_{1, i t}+X_{2, i t}+\ldots+X_{S, i t}\right)+t_{t}+e_{i t}$

where Transition $_{i t}$ is a binary variable indicating annual changes in employment type between year $t-1$ and year $t . X_{1, i t}, X_{2, i t}, \ldots, X_{S, i t}$ are demographic variables, including age, gender, marital status, having any children, long-standing health problems, current occupational status and highest educational achievement. The term $t_{t}$ represents a vector of year indicators, accounting for exogenous economic conditions which potentially influence individual labour market trajectories. Finally, $e_{i t}$ is the random error term. The estimates we obtained by fitting this linear model can be considered as the upper boundaries of the psychological impact of the transitions.

In order to rule out unobserved heterogeneity, possibly causing selection bias, the relationship between employment transitions and variation in psychological distress was estimated using individual fixed effects. Individual-specific characteristics, such as personality traits or endogenous susceptibility to distress, which cannot be observed and do not change over time, could predict both changes in psychological well- being and transition events. Fixed effects adjust for all time-invariant characteristics that could simultaneously affect psychological health and predict employment transitions. We estimate the following specification:

$D_{i t}=a+\beta_{1}$ Transition $_{i t}+\beta_{2 S}\left(X_{1, i t}+X_{2, i t}+\ldots+X_{S, i t}\right)+t_{t}+\gamma_{i}+u_{i t}$

where $\gamma_{i}$ stands for the individual-specific, time-invariant effects and $u_{i t}$ is the rando bn $\mathrm{m}$ error term. $X_{1, i t}, X_{2, i t}, \ldots, X_{S, i t}$ are all demographic variables that may change over time. Time-invariant socio-economic characteristics, such as gender, mental health prior to the transition and cognitive ability during childhood, are not adjusted for separately. The influence of such characteristics is ruled out by demeaning all variables included in the specification. Within-individual unobserved heterogeneity is adjusted for, by using individual variation around the means to gauge the effects of employment transitions on changes in psychological distress over time. Therefore, bias caused by unobserved, timeinvariant factors is reduced, facilitating the inference of the link from employment transitions to changes in psychological health over long labour market trajectories.

The likelihood that job-related characteristics are pathways linking transitions from and to underemployment to changes in distress levels is explored by including these factors in the estimated model. Potential reactions of the estimated psychological effect of employment transitions to the inclusion of job earnings and job security in the models reveal whether these characteristics explain the psychological repercussions of hours-underemployment.

\subsection{Results}

\subsubsection{Association between underemployment and distress}

The difference in the GHQ caseness scores between those who remained in underemployment and those who would move to a full-time job was negligible before the transition $(\beta=0.14, S E=0.18, p>0.1$, $95 \% C I[-0.22,0.50])$ in year $t-1$. After the transition has occurred, in year $t$, those who switched to full-time employment demonstrated significantly reduced distress levels $(\beta=0.45, S E=0.17, p<0.01$, $C I=[0.11,0.79])$. This result suggests that reverse causality is not a key factor, as illustrated in the upper panel of Fig. 2. Yet, this does not hold for those initially working full-time and then, moving to hoursunderemployment. Full-time workers who would retain their position in the market demonstrate substantially lower psychological distress levels compared to those who were about to switch to underemployment in the next year $(\beta=-0.79, S E=0.17, p<0.001,95 \%$ $C I[-1.12,-0.47])$. After the transition, the difference between psychological distress experienced by those who moved to full-time employment compared and the study subjects who remained in underemployment rises in absolute value, potentially as a result of the transition (Mean difference $=-0.96, S E=0.17, p<0.001, C I=[-$ $1.30,-0.63])$. However, the difference in psychological health before the transition event could be attributed to expectations regarding the forthcoming change in labour market status. It could also suggest selfselection into underemployment due to poor psychological health. Adopting the fixed-effects estimation framework, we adjust for individual heterogeneity, which could result in self-selection into moving between employment types.

\subsubsection{Underemployment OLS and fixed effects regressions}

Table 2 presents the transition coefficients resulting from the estimation of the specifications linking changes in psychological distress to switches between employment types, using OLS (upper panel) and fixed-effects (bottom panel) estimation techniques. The baseline models (models 5 and 6 without controls for socio-economic confounders) only account for the influence of year effects while in the extended models the full set of socio-demographic confounding factors is added. Net weekly earnings and individual feelings about job security were added separately in the extended models. All models were estimated 


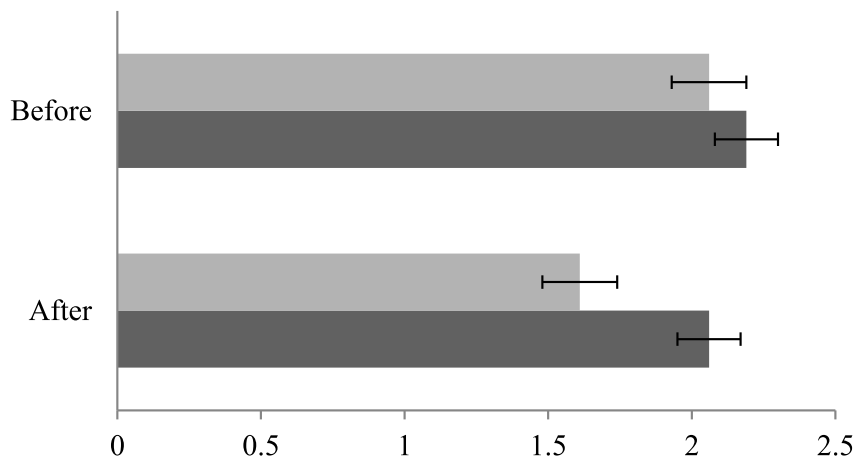

Transition

- No transition
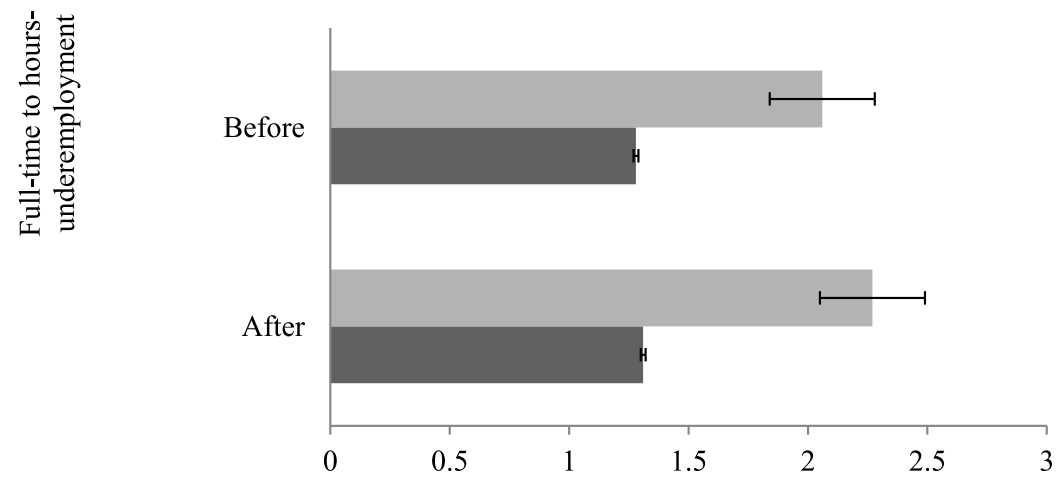

Transition

No transition

Fig. 2. Mean distress levels before and after employment transitions. This figure shows differences in distress between workers who switched between employment types and those who did not.

Table 2

Changes in Underemployment and Psychological Distress in the British Household Panel Study using Ordinary Least Squares (top panel) and Fixed Effects Models (bottom).

\begin{tabular}{|c|c|c|}
\hline \multirow[t]{3}{*}{ Pooled Sample (OLS) } & \multicolumn{2}{|c|}{ Psychological Distress } \\
\hline & \multicolumn{2}{|l|}{$\begin{array}{l}\text { Full-time to } \\
\text { underemployment } \\
\text { transition }\end{array}$} \\
\hline & $\beta(\mathrm{SE})$ & $\beta(S E)$ \\
\hline Underemployment $^{\mathrm{a}}$ & $0.381 * * *(0.092)$ & $-0.183^{* * *}(0.050)$ \\
\hline $\begin{array}{c}\text { socio-economic } \\
\text { confounders }^{b}\end{array}$ & $0.328^{* * *}(0.091)$ & $-0.143^{* * *}(0.052)$ \\
\hline + weekly net earnings & $0.293 * * *(0.091)$ & $-0.181^{* * *}(0.061)$ \\
\hline+ job security & $0.280 * * *(0.091)$ & $-0.123^{* *}(0.052)$ \\
\hline$N$ (person-year) & 37,234 & 2145 \\
\hline \multicolumn{3}{|c|}{ Panel Sample (Fixed Effects) } \\
\hline Underemployment $^{\mathrm{a}}$ & $0.185 * *(0.094)$ & $-0.178^{* * *}(0.058)$ \\
\hline $\begin{array}{c}\text { socio-economic } \\
\text { confounders }{ }^{c}\end{array}$ & $0.184 * *(0.094)$ & $-0.156^{* * *}(0.060)$ \\
\hline + weekly net earnings & $0.162 *(0.095)$ & $-0.160 * *(0.074)$ \\
\hline+ job security & $0.168 *(0.094)$ & $-0.153^{* *}(0.060)$ \\
\hline$N$ (person-year) & 37,234 & 2145 \\
\hline
\end{tabular}

$* * * p<0.01, * * p<0.05, * p<0.1$.

Note. Standardised coefficients are reported. Standard errors are included in parentheses.

a Model controls only for year effects.

b Socioeconomic confounders are gender, age (and squared age term), marital status, having at least one child, highest academic qualification, longstanding illness and current occupational status (professional/managerial/ skilled non manual/skilled manual/partly skilled/unskilled).

${ }^{c}$ Socioeconomic confounders include all the variables reported above apart from gender. separately for each type of transition.

Switching from underemployment to a full-time job appears was associated with a reduction in psychological distress while moving from full-time employment to underemployment predicted elevated distress levels. Adjusting for time-invariant individual characteristics did not markedly attenuate the potential psychological health effects of employment transitions. In the bottom panel of Table 2, which displays estimates of the effect of transitions on psychological distress in the fixed-effects models, moving from full-time employment to underemployment predicted an increase in stress of $0.18 \mathrm{SD}(S E=0.09$, $p<0.05,95 \%$ CI $[0.00,0.37])$, after adjusting for the influence of individual socio-economic background. Conversely, moving from underemployment to full-time work forecasted an increase in distress levels by approximately $0.16 \mathrm{SD}(S E=0.06, p<0.001,95 \% C I[-0.27$, $-0.04]$ ), after adjustment for observable demographic characteristics.

As shown in Table 2, introducing job security and net earnings controls into the models reduces the magnitude of the psychological impact of moving between underemployment and a full-time job.

\subsubsection{Supplementary analysis}

Supplementary analysis including extended controls on having children (i.e. having young children up to six years old and/or babies) suggested that the impact of transitions between underemployment and full-time employment does not depend on these aspects of workers' family life. Further, controlling for sector of occupation did not substantially impact the magnitude of the relationship between moving between full-time employment and underemployment and psychological distress levels across our regression models (see Appendix B, Section 4 in Supplementary Materials).

Analysing transitions between alternative employment situations yielded essentially similar results to our sensitivity tests discussed in 
Study 1. As shown in Table B2 in Supplementary Materials, when satisfied with number of weekly working hours, transitions between parttime and full-time employment do not predict any changes in psychological health. In contrast, switching from full-time employment to underemployment does predict increased distress levels among workers who prefer to work more hours $(\beta=0.27, S E=0.13, p<0.05,95 \%$ $C I[-0.02,0.50])$. As shown in Table B3, moving from full-time to parttime employment does not have any substantial impact on psychological distress in itself $(\beta=0.01, S E=0.03, p>0.1,95 \% C I[-0.06$, $0.06]$ ), while wanting to work more hours is associated with slightly increased distress levels $(\beta=0.07, S E=0.02, p<0.001,95 \% C I$ $[0.03,0.11]$ ). Taken together, supplementary analysis suggests that the combination of working part-time and preferring to work more hours predicts the largest increase in individual distress levels.

\section{Discussion}

In this study, we used two representative British samples to uncover evidence that underemployment predicts elevated psychological distress levels both at a single point in time and across employment transitions. Our study is unique in that we operationalised the International Labour Organization (1998) definition of underemployment in order to estimate the potential effect of underemployment on distress levels using advanced analytical techniques. Specifically, we defined underemployment as working below $30 \mathrm{~h}$ per week in the UK context and preferring to work more hours.

In Study 1 our measure of underemployment predicted elevated distress levels among UK workers at age $42(\beta=0.25)$, after adjusting for confounding factors using propensity score matching. Study 2 showed that moving from full-time employment to underemployment was associated with increased distress levels $(\beta=0.19)$ over 18 years of observations and after accounting for time-invariant unobserved heterogeneity using fixed effects. The latter association was comparable to longitudinal estimates of the mental health effect of becoming unemployed $(d=0.19$; Paul and Moser, 2009). Our results also speak to the potential reversibility of the adverse psychological consequences of hours-underemployment. Hours-underemployed workers who transitioned into full-time positions experienced a decrease in distress that closely matched the increase associated with becoming hours-underemployed.

In the present article, we contribute to existing literature by extending prior studies that have: (i) either not considered the willingness of workers to work more hours (e.g. Bardasi and Francesconi, 2004), or (ii) focused on the relationships between working hours preferences and life satisfaction (e.g. Wunder and Heineck, 2013), which is a cognitive evaluation with rather little relevance to health, without considering employment type (i.e. full-time or part-time), and finally, (iii) not addressed appropriately reverse causality and self-selection biases (Friedland and Price, 2003).

Testing alternative combinations of working part-time and working time preferences revealed that it is working less than $30 \mathrm{~h}$ per week and preferring to work longer hours that predicts psychological distress rather than part-time employment or working-hours preferences per se. Our analyses pointed to some minor psychological impacts of experiencing either working fewer hours than a specific threshold or preferences for additional working hours. In contrast, the combination of working less than $30 \mathrm{~h}$ per week and preferring to work more hours was associated with the greatest and most consistent increases in psychological distress.

Taken as a whole, our findings indicate that the well-being effects observed in two lines of literature - the first examining relationships between well-being and part-time employment (e.g. Bardasi and Francesconi, 2004; Rodriguez, 2002), and the second linking well-being and working hours preferences (e.g. Wunder and Heineck, 2013) - are likely to be driven by a group of part-time workers who would prefer to work longer hours. We suggest that this result occurred because being available for more hours of work predicts financial strain (Warren, 2015; Wunder and Heineck, 2013) and part-time employment is associated with earnings inequality, low occupational status and less secure (OECD, 2010) and low-quality jobs (Horemans et al., 2016; McGovern et al., 2004).

Our analyses showed that job earnings and feelings about job security could partly explain the psychological impact of underemployment among workers who would ideally work longer hours. While this finding points to pathways through which underemployment may have detrimental welfare effects, on average job earnings and perceptions of job security explained a small $(\approx 10 \%)$ portion of the psychological impact of hours-underemployment. The precarious nature of underemployment and inferior working conditions that have been reported previously (Horemans et al., 2016; McGovern et al., 2004) were likely not fully captured by our income and job security measures. Moreover, in the UK the effectiveness of the policies implemented to prevent unfavourable treatment of part-time workers and improe quality of part-time jobs has been criticised (e.g. Bell, 2011). Therefore, a suggestion for future work aiming to explore the psychological harm caused by underemployment is an extensive analysis of the paths linking underemployment to poor psychological health.

\subsection{Strengths and limitations}

Our study was mainly limited by data constraints. First, we used self-reported measures of psychological distress, which are prone to measurement error. Despite GHQ-12 being a valid measure of common mental health disorders in public surveys (e.g. Lundin et al., 2016), it is subject to self-report bias as opposed to objective psychological health assessments by professionals. Moreover, the data we use do not reflect contemporary experiences of work; the contemporaneous associations between underemployment and psychological well-being were observed in 2000 while the long-term links between transitions from and to underemployment and variations in psychological health were monitored in the period between 1991 and 2009.

While we uncover evidence of the potentially damaging effects of underemployment on psychological health, the impact of contemporary working-hours contracts and workers' preferences on their psychological well-being remains unclear. Another limitation is that we were not able to control for all socio-economic factors potentially influencing adult psychological health and selection into underemployment, such as non-cognitive skills (Heckman et al., 2006), mental health prior to labour market entry (Fletcher, 2013), living in poverty (Lund et al., 2010) and parenting and family conditions at early childhood (Allen et al., 2014). However, adjusting for a wide set of observed socio-economic factors and time-invariant unobservable traits did not offset the associations under study, suggesting that there is a robust link from underemployment to elevated psychological distress, which is not accounted for by potentially confounding factors.

Although we demonstrated that this association is robust, further research is now needed to identify whether the welfare effects of transitioning into and out of underemployment are transient or sustained over time. An extensive theoretical literature (e.g. adaptationlevel theory, set-point theory, dynamic equilibrium theory) suggests that the welfare effects of important life events may be short-lived. Yet, empirical support for this notion is mixed. Prospective studies have shown that in some cases life-circumstances may provoke prolonged changes in well-being (Luhmann et al., 2012). In particular, the wellbeing consequences of unemployment have been shown to persist even after reemployment (Clark et al., 2001; Luhmann et al., 2012; Mousteri et al., 2018). However, other longitudinal studies have shown marked improvements in mental health among unemployed people following reemployment (Paul and Moser, 2009). In this study, we observed a substantial reduction in distress levels when hours-underemployed employees returned to full-time work. Identifying whether complete adaptation can occur when people remain hours-underemployed for 
several years requires further research.

Further, while we found that underemployment was distressing even after accounting for the presence of young children and sector of employment, data limitations did not allow for a comprehensive analysis of the psychological consequences of underemployment for specific groups of workers (e.g., women returning to the labour market after giving birth, workers in particular sectors). Further research is necessary to disentangle the psychological implications of underemployment for those most likely to find themselves in underemployment, and within individual sectors where working conditions may amplify the impact of hours-underemployment.

\section{Conclusions}

In sum, our findings draw attention to the psychological health impact of underemployment - a prevalent type of inadequate employment and a major case of labour underutilisation. Research drawing on contemporary survey data may uncover similar distressing effects of emergent experiences of underemployment, such as zero-hours contracts. Given that mental health difficulties place individuals at risk of job loss (e.g. Egan et al., 2016; Mousteri et al., 2019) developing a comprehensive understanding of the psychological impact of underemployment may be crucial in preventing labour force detachment.

\section{Appendix A. Supplementary data}

Supplementary data to this article can be found online at https:// doi.org/10.1016/j.socscimed.2019.112641.

\section{References}

Allen, J., Balfour, R., Bell, R., Marmot, M., 2014. Social determinants of mental health. Int. Rev. Psychiatry 26 (4), 392-407.

Angrave, D., Charlwood, A., 2015. What is the relationship between long working hours, over-employment, under-employment and the subjective well-being of workers? Longitudinal evidence from the UK. Hum. Relat. 68 (9), 1491-1515.

Bardasi, E., Francesconi, M., 2004. The impact of atypical employment on individual wellbeing: evidence from a panel of British workers. Soc. Sci. Med. 58 (9), 1671-1688.

Başlevent, C., Kirmanoğlu, H., 2014. The impact of deviations from desired hours of work on the life satisfaction of employees. Soc. Indic. Res. 118 (1), 33-43.

Bell, M., 2011. Achieving the objectives of the part-time work directive? Revisiting the part-time workers regulations. Ind. Law J. 40 (3), 254-279.

Bell, D.N., Blanchflower, D.G., 2013. Underemployment in the UK revisited. National Institute Economic Review 224 (1), F8-F22.

Booth, A.L., Francesconi, M., 2003. Union coverage and non-standard work in Britain. Oxf. Econ. Pap. 55, 383-416.

Booth, A.L., Van Ours, J.C., 2008. Job satisfaction and family happiness: the part-time work puzzle. Econ. J. 118 (526), F77-F99.

Booth, A.L., Van Ours, J.C., 2009. Hours of work and gender identity: does part-time work make the family happier? Economica 76 (301), 176-196.

Burton, P., Gurrin, L., Sly, P., 1998. Extending the simple linear regression model to account for correlated responses: an introduction to generalized estimating equations and multi-level mixed modelling. Stat. Med. 17 (11), 1261-1291.

Caliendo, M., Kopeinig, S., 2008. Some practical guidance for the implementation of propensity score matching. J. Econ. Surv. 22 (1), 31-72.

Clark, A., Georgellis, Y., Sanfey, P., 2001. Scarring: the psychological impact of past unemployment. Economica 68 (270), 221-241.

Cornaglia, F., Crivellaro, E., McNally, S., 2015. Mental health and education decisions. Labour Econ. 33, 1-12.

Daly, M., Delaney, L., 2013. The scarring effect of unemployment throughout adulthood on psychological distress at age 50: estimates controlling for early adulthood distress and childhood psychological factors. Soc. Sci. Med. 80, 19-23.

Deary, I.J., Taylor, M.D., Hart, C.L., Wilson, V., Smith, G.D., Blane, D., Starr, J.M., 2005. Intergenerational social mobility and mid-life status attainment: influences of childhood intelligence, childhood social factors, and education. Intelligence 33 (5), 455-472.

Dehejia, R.H., Wahba, S., 1999. Causal effects in non-experimental studies: Re-evaluating the evaluation of training programs. J. Am. Stat. Assoc. 94 (448), 1053-1062.

Dehejia, R.H., Wahba, S., 2002. Propensity score matching methods for non-experimental causal studies. Rev. Econ. Stat. 84 (1), 151-161.

Dooley, D., Prause, J., Ham-Rowbottom, K.A., 2000. Underemployment and depression: longitudinal relationships. J. Health Soc. Behav. 41, 421-436.

Egan, M., Daly, M., Delaney, L., 2016. Adolescent psychological distress, unemployment, and the Great recession: evidence from the national longitudinal study of youth 1997. Soc. Sci. Med. 156, 98-105.
Fagan, C., Rubery, J., Smith, M., 2013. Womens' Employment in Europe: Trends and Prospects. Routledge, London.

Feldman, D.C., Leana, C.R., Turnley, W.H., 1997. A relative deprivation approach to understanding underemployment. Cooper, C.L., Rousseau, D.M. (Eds.), Trends Organ. Behav. 4, 43-60.

Ferrie, J.E., Shipley, M.J., Stansfeld, S.A., Marmot, M.G., 2002. Effects of chronic job insecurity and change in job security on self-reported health, minor psychiatric morbidity, physiological measures, and health related behaviours in British civil servants: the Whitehall II study. J. Epidemiol. Community Health 56 (6), 450-454.

Fletcher, J., 2013. Adolescent depression and adult labor market outcomes. South. Econ. J. 80 (1), 26-49.

Friedland, D.S., Price, R.H., 2003. Underemployment: consequences for the health and well-being of workers. Am. J. Community Psychol. 32 (1-2), 33-45.

Goldberg, D.P., Williams, P., 1988. A User's Guide to the General Health Questionnaire. Windsor: NFER, Nelson.

Hanley, J.A., Negassa, A., Forrester, J.E., 2003. Statistical analysis of correlated data using generalized estimating equations: an orientation. Am. J. Epidemiol. 157 (4), 364-375.

Heckman, J.J., Stixrud, J., Urzua, S., 2006. The effects of cognitive and noncognitive abilities on labor market outcomes and social behavior. J. Labor Econ. 24 (3), $411-482$.

Heyes, J., Tomlinson, M., Whitworth, A., 2017. Underemployment and well-being in the UK before and after the Great recession. Work Employ. Soc. 31 (1), 71-89.

Hobfoll, S.E., 1989. Conservation of resources: a new attempt at conceptualizing stress. Am. Psychol. 44 (3), 513-524.

Horemans, J., Marx, I., Nolan, B., 2016. Hanging in, but only just: part-time employment and in-work poverty throughout the crisis. IZA J. Eur. Labor Stud. 5 (5).

ILO, 1998. Resolution Concerning the Measurement of Underemployment and Inadequate Employment Situations, Adopted by the Sixteenth International Conference of Labour Statisticians. [online] Available at: https://www.ilo.org/wcmsp5/groups/public/— dgreports/—stat/documents/normativeinstrument/wcms_087487.pdf Accessed on 02-01-2017.

Jahoda, M., 1982. Employment and Unemployment: A Social-Psychological Analysis. Cambridge University Press, Cambridge, England.

Richardson, H., Kamerade, D., 2018. Gender segregation, underemployment and subjective well-being in the UK labour market. Hum. Relat. 71 (2), 285-309.

Kim, M.H., Kim, C.Y., Park, J.K., Kawachi, I., 2008. Is precarious employment damaging to self-rated health? Results of propensity score matching methods, using longitudinal data in South Korea. Soc. Sci. Med. 67 (12), 1982-1994.

Koenen, K.C., Moffitt, T.E., Roberts, A.L., Martin, L.T., Kubzansky, L., Harrington, H., Poulton, R., Caspi, A., 2009. Childhood IQ and adult mental disorders: a test of the cognitive reserve hypothesis. Am. J. Psychiatry 166 (1), 50-57.

Koltai, J., Bierman, A., Schieman, S., 2018. Financial circumstances, mastery, and mental health: taking unobserved time-stable influences into account. Soc. Sci. Med. 202, $108-116$.

Latack, J.C., Kinicki, A.J., Prussia, G.E., 1995. An integrative process model of coping with job loss. Acad. Manag. Rev. 20 (2), 311-342.

Lepinteur, A., 2019. Working time mismatches and self-assessed health of married couples: evidence from Germany. Soc. Sci. Med. 235, 112410.

Luhmann, M., Hofmann, W., Eid, M., Lucas, R.E., 2012. Subjective well-being and adaptation to life events: a meta-analysis. J. Personal. Soc. Psychol. 102 (3), 592-615.

Lund, C., Breen, A., Flisher, A.J., Kakuma, R., Corrigall, J., Joska, J.A., Swartz, L., Patel, V., 2010. Poverty and common mental disorders in low and middle income countries: a systematic review. Soc. Sci. Med. 71 (3), 517-528.

Lundin, A., Hallgren, M., Theobald, H., Hellgren, C., Torgén, M., 2016. Validity of the 12 item version of the General Health Questionnaire in detecting depression in the general population. Public Health 136, 66-74.

Makowska, Z., Merecz, D., Moscicka, A., Kolasa, W., 2002. The validity of general health questionnaires, GHQ-12 and GHQ-28, in mental health studies of working people. Int. J. Occup. Med. Environ. Health 15 (4), 353-362.

McGovern, P., Smeaton, D., Hill, S., 2004. Bad jobs in Britain: nonstandard employment and job quality. Work Occup. 31 (2), 225-249.

McKee-Ryan, F.M., Harvey, J., 2011. "I have a job, but...": a review of underemployment. J. Manag. 37 (4), 962-996.

Milner, A., LaMontagne, A.D., 2017. Underemployment and mental health: comparing fixed- effects and random-effects regression approaches in an Australian working population cohort. Occup. Environ. Med. 74, 344-350.

Mousteri, V., Daly, M., Delaney, L., 2018. The scarring effect of unemployment on psychological well-being across Europe. Soc. Sci. Res. 72, 146-169.

Mousteri, V., Daly, M., Delaney, L., Tynelius, P., Rasmussen, F., 2019. Adolescent mental health and unemployment over the lifespan: population evidence from Sweden. Soc. Sci. Med. 222, 305-314.

Ng, W.H.T., Feldman, D.C., 2014. Subjective career success: a meta-analytic review. J. Vocat. Behav. 85 (2), 169-179.

OECD, 2010. OECD Employment Outlook 2010: Moving beyond the Jobs Crisis. OECD Publishing, Paris.

OECD, 2014. OECD Employment Outlook 2014. OECD Publishing, Paris. https://doi.org/ 10.1787/empl_outlook-2014-en.

OECD, 2018. OECD Employment Outlook 2018. OECD Publishing, Paris.

Office for National Statistics, 2018. Labour Market Economic Commentary: July 2018. [online] Available at: https://www.ons.gov.uk/employmentandlabourmarket/ peopleinwork/employmentandemployeetypes/articles/ labourmarketeconomiccommentary/july2018 Accessed on 18 September 2018.

Page, A., Milner, A., Morrell, S., Taylor, R., 2013. The role of under-employment and unemployment in recent birth cohort effects in Australian suicide. Soc. Sci. Med. 93 $155-162$. 
Paul, K.I., Batinic, B., 2010. The need for work: jahoda's latent functions of employment in a representative sample of the German population. J. Organ. Behav. 31 (1), 45-64.

Paul, K.I., Moser, K., 2009. Unemployment impairs mental health: meta-analyses. J. Vocat. Behav. 74 (3), 264-282.

Prause, J., Dooley, D., 1997. Effect of underemployment on school-leavers' self-esteem. J. Adolesc. 20 (3), 243-260.

Rodriguez, E., 2002. Marginal employment and health in Britain and Germany: does unstable employment predict health? Soc. Sci. Med. 55 (6), 963-979.

Rosenbaum, P.R., Rubin, D.B., 1985. Constructing a control group using multivariate matched sampling methods that incorporate the propensity score. Am. Stat. 39, 33-38.

Sidi, Y., Harel, O., 2018. The treatment of incomplete data: reporting, analysis, reproducibility, and replicability. Soc. Sci. Med. 209, 169-173.

Stuart, E.A., 2010. Matching methods for causal inference: a review and a look forward. Stat. Sci.: A Rev. J. Inst. Math. Stat. 25 (1), 1-21.

Sverke, M., Hellgren, J., Näswall, K., 2002. No security: a meta-analysis and review of job insecurity and its consequences. J. Occup. Health Psychol. 7 (3), 242-264.

Taylor, M.F. (Ed.), 2010. British Household Panel Survey User Manual: Volume A: Introduction, Technical Report and Appendices. University of Essex, Colchester.

Virtanen, P., Vahtera, J., Kivimäki, M., Pentti, J., Ferrie, J., 2002. Employment security and health. J. Epidemiol. Community Health 56 (8), 569-574.

Warren, T., 2015. Work-time underemployment and financial hardship: class inequalities and recession in the UK. Work Employ. Soc. 29 (2), 191-212.

Wilkins, R., 2007. The consequences of underemployment for the underemployed. J. Ind. Relat. 49 (2), 247-275.

Wooden, M., Warren, D., Drago, R., 2009. Working time mismatch and subjective well-being. Br. J. Ind. Relat 47 (1), 147-179.

Wunder, C., Heineck, G., 2013. Working time preferences, hours mismatch and well-being of couples: are there spillovers? Labour Econ. 24, 244-252.

Zimmerman, F.J., Katon, W., 2005. Socioeconomic status, depression disparities, and financial strain: what lies behind the income-depression relationship? Health Econ. 14 (12), 1197-1215. 